\title{
DESIGN STUDY \\ OF THE INJECTION AND EXTRACTION ELEMENTS FOR THE RIKEN SUPERCONDUCTING RING CYCLOTRON
}

T. Tominaka, H. Okuno, S. Fujishima, T. Mitsumoto, T. Kubo, T. Kawaguchi, Y. Tanaka, J. -W. Kim, K. Ikegami, N. Sakamoto, S. Yokouchi, T. Morikawa, A. Goto, and Y. Yano The Institute of Physical and Chemical Research (RIKEN), Wako, Saitama, 351-01, Japan

\section{Abstract}

The injection system for the RIKEN 6-sector superconducting ring cyclotron (SRC) consists of four bending magnets (BM1, BM2, BM3, BM4), three magnetic inflection channels (MIC1, MIC2, MIC3), and an electrostatic inflection channel (EIC). The four bending magnets and one of the three magnetic channels are superconducting. In this paper, the status of the design study of the BM1 is reported.

\section{INTRODUCTION}

The injection and extraction systems of the RIKEN 6sector superconducting ring cyclotron (SRC) are designed. $[1,2,3,4]$ It is required that the disturbance due to the bending magnets in the acceleration region should be less than $100 \mathrm{G}$. Two types of bending magnets - with an iron yoke or a shield coil - have been studied. A stray field up to $0.6 \mathrm{~T}$ is anticipated in the area of the BM1 due to the saturation of iron yoke of the main SRC's sector magnet, depending on ions. Then, if the BM1 has an iron yoke, the iron yoke saturates due to the stray field. Such saturation of the iron yoke was simulated by the field calculation, with 3D electromagnetic calculation code TOSCA, for the complete configuration of 6-sector magnets. As a result, it was found that the iron yoke is ineffective due to the stray fields of up to $0.6 \mathrm{~T}$ from the sector magnets, and an active-shield type magnet, which is equipped with shield coils, is adopted for the BM1 close to the sector magnets. The magnetic inflection channels are also designed to be an active shield type. In this paper, we discuss about the design of the injection bending magnet BM1, in particular about the optimization of the cross-sectional shape of the BM1. Major parameters of BM1 are shown in Table 1.

Table 1. Major parameter of BM1

\begin{tabular}{|l|l|}
\hline Bending field & $4.0 \mathrm{~T}$ \\
\hline Bore size & $40(\mathrm{H}) \times 20(\mathrm{~V}) \mathrm{mm}^{2}$ \\
\hline $\begin{array}{l}\text { Uniformity } \\
\text { (excluding quadrupole) }\end{array}$ & $1 \times 10^{-3}$ \\
\hline Bending radius & $1.32 \mathrm{~m}$ \\
\hline $\begin{array}{l}\text { Effective magnetic angle } \\
\text { (length) }\end{array}$ & $52^{\circ}$ \\
\hline Stray field & $(1.20 \mathrm{~m})$ \\
\hline
\end{tabular}

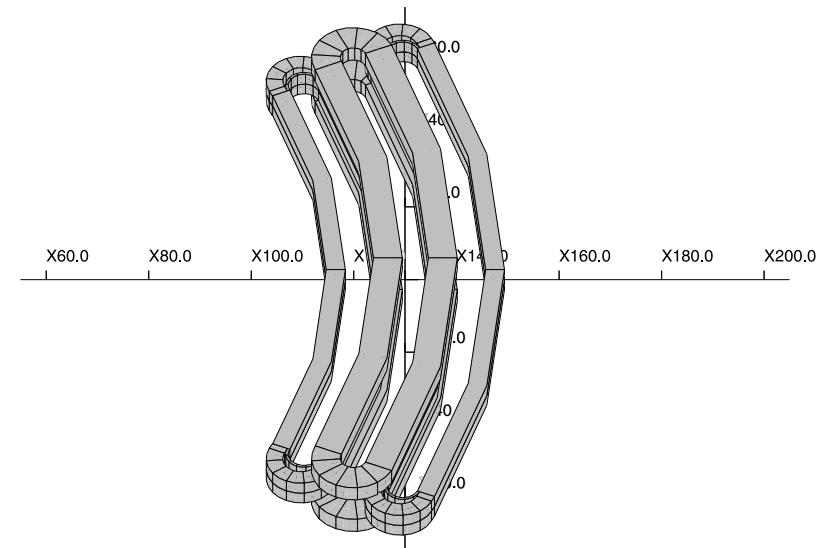

Fig. 1. Schematic view of the bending magnet (BM1)

\section{OPTIMIZATION OF CROSS SECTIONAL SHAPE FOR BM1}

The BM1 is planned to be composed of rectangular coil blocks. Then, the procedure of the optimization for the cross sectional shape is as follows:

1) calculation of the multipoles determined from the cross sectional configuration of coil,

2) search of the minimum value of field uniformity from these multipoles

\subsection{Calculation of the Multipoles}

For four helical current blocks, current density $\pm \mathrm{j}_{\mathrm{z}}$, $\mathrm{x}$-coordinate $\pm \mathrm{x}_{1}, \pm \mathrm{x}_{2}, \mathrm{y}$-coordinate $\pm \mathrm{y}_{1}, \pm \mathrm{y}_{2}$, with dipole symmetry, the interior normal multipoles $B_{n}$ for $r<$ $\sqrt{\mathrm{x}_{1}{ }^{2}+\mathrm{y}_{1}{ }^{2}}$, are given as follows, $[5,6,7]$

$$
\left\{\begin{array}{c}
\mathrm{B}_{1}\left(\mathrm{x}_{1}, \mathrm{x}_{2}, \mathrm{y}_{1}, \mathrm{y}_{2}\right)=\mathrm{B}_{\mathrm{ref}}\left(\mathrm{x}_{1}, \mathrm{x}_{2}, \mathrm{y}_{1}, \mathrm{y}_{2}\right)= \\
\mathrm{B}_{1}\left(\mathrm{x}_{2}, \mathrm{y}_{2}\right)-\mathrm{B}_{1}\left(\mathrm{x}_{1}, \mathrm{y}_{2}\right)-\mathrm{B}_{1}\left(\mathrm{x}_{2}, \mathrm{y}_{1}\right)+\mathrm{B}_{1}\left(\mathrm{x}_{1}, \mathrm{y}_{1}\right) \\
\mathrm{B}_{\mathrm{n}}\left(\mathrm{x}_{1}, \mathrm{x}_{2}, \mathrm{y}_{1}, \mathrm{y}_{2}\right)=\mathrm{B}_{\mathrm{n}}\left(\mathrm{x}_{2}, \mathrm{y}_{2}\right)-\mathrm{B}_{\mathrm{n}}\left(\mathrm{x}_{1}, \mathrm{y}_{2}\right)- \\
\mathrm{B}_{\mathrm{n}}\left(\mathrm{x}_{2}, \mathrm{y}_{1}\right)+\mathrm{B}_{\mathrm{n}}\left(\mathrm{x}_{1}, \mathrm{y}_{1}\right), \quad \mathrm{n}=3,5, \ldots
\end{array}\right.
$$

where

$$
\left\{\begin{array}{c}
\mathrm{B}_{1}(\mathrm{x}, \mathrm{y})=\mathrm{B}_{\mathrm{ref}}(\mathrm{x}, \mathrm{y})= \\
-\frac{\mu_{0} \mathrm{j}_{\mathrm{z}}}{\pi}\left\{2 \mathrm{x}_{0} \tan ^{-1}\left(\frac{\mathrm{y}}{\mathrm{x}}\right)+\mathrm{y}_{0} \log \left(\frac{\mathrm{x}^{2}+\mathrm{y}^{2}}{\mathrm{x}^{2}}\right)\right\} \\
\mathrm{B}_{\mathrm{n}}(\mathrm{x}, \mathrm{y})=\frac{2 \mu_{0} \mathrm{j}_{\mathrm{z}}}{\pi} \frac{1}{(\mathrm{n}-1)(\mathrm{n}-2)} \frac{\mathrm{r}_{0} \mathrm{n}-1}{\sqrt{\mathrm{x}^{2}+\mathrm{y}^{2 \mathrm{n}-2}}} \times \\
\sin \left[(\mathrm{n}-2) \tan ^{-1}\left(\frac{\mathrm{y}}{\mathrm{x}}\right)\right], \quad \mathrm{n}=3,5, \cdots
\end{array}\right.
$$




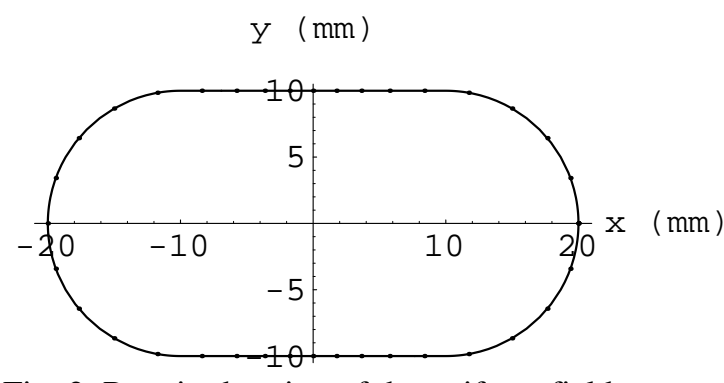

Fig. 2. Required region of the uniform field.

where $\mathrm{r}_{0}$ is the reference radius, and the normal multipole coefficients $b_{n}$ is defined as $b_{n}=B_{n} / B_{1}$.

\subsection{Relation between Field Uniformity and Multipole Coefficients for Dipole Coils}

The interior magnetic field of 2-dimensional dipole coil with the infinite length is given as follows, on the European definition, [8]

$B_{y}(r, \theta)=B_{r e f} \sum_{n=1}^{\infty}\left(\frac{r}{r_{0}}\right)^{n-1}\left\{a_{n} \sin [(n-1) \theta]+b_{n} \cos [(n-1) \theta]\right\}$.

Then, for the case with the dipole symmetry, $a_{n}=b_{2 n}=0$ for $n=1,2,3, \ldots, \infty$, the $y$ component of field, $\operatorname{By}(r, \theta)$ becomes, with $\mathrm{b}_{1}=1$,

$$
\begin{gathered}
B_{y}(r, \theta)=B_{\text {ref }} \sum_{n=1,3,5}^{\infty}\left(\frac{r}{r_{0}}\right)^{n-1} b_{n} \cos [(n-1) \theta]= \\
B_{\text {ref }}\left(1+b_{3}\left(\frac{r}{r_{0}}\right)^{2} \cos 2 \theta+b_{5}\left(\frac{r}{r_{0}}\right)^{4} \cos 4 \theta+\right. \\
\left.b_{7}\left(\frac{r}{r_{0}}\right)^{6} \cos 6 \theta+\ldots\right)
\end{gathered}
$$

Then,

$$
\begin{aligned}
& \left|\frac{B_{y}(r, \theta)-B_{r e f}}{B_{r e f}}\right|=\left|\frac{B_{y}(r, \theta)-B_{y 0}}{B_{y 0}}\right|= \\
& \mid b_{3}\left(\frac{r(\theta)}{r_{0}}\right)^{2} \cos 2 \theta+b_{5}\left(\frac{r(\theta)}{r_{0}}\right)^{4} \cos 4 \theta+b_{7}\left(\frac{r(\theta)}{r_{0}}\right)^{6} \cos 6 \theta+\ldots
\end{aligned}
$$

The required condition of multipole coefficients depends on the shape of the uniform region where the field uniformity is prescribed. The shape of the uniform field region for BM1 is shown in Fig.2. Therefore, the requirement condition for the normal multipoles can be calculated from the prescribed uniformity of the dipole field $\mathrm{B}_{\mathrm{y}}$ at the boundary points of the region shown in Fig.2, using Eq.(5). For the coil with the dipole symmetry, the resultant satisfying regions of sextupole and decapole, ( $\left.\mathrm{b}_{3}, \mathrm{~b}_{5}\right)$ of $\left|\left(\mathrm{B}_{\mathrm{y}}-\mathrm{B}_{\mathrm{y} 0}\right) / \mathrm{B}_{\mathrm{y} 0}\right|$ of $<0.1 \%$, in the case of $b_{7}, b_{9}, \cdots=0$, is shown as the central white

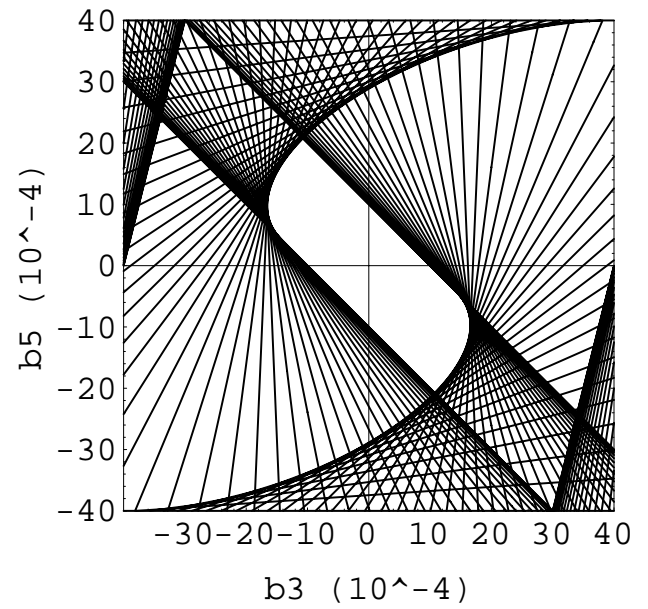

Fig. 3. (b3, b5) region of $<0.1 \%$ of $|(\mathrm{By}-\mathrm{By} 0) / \mathrm{By} 0|$ with $b_{7}=0$ and, b9, $b_{11}, \ldots=0$.

zone in Fig.3. As a result, the field uniformity $U$, which is defined as the maximum value of $\left|\left(\mathrm{B}_{\mathrm{y}}(\mathrm{r}, \theta)-\mathrm{B}_{\mathrm{y}} 0\right) / \mathrm{B}_{\mathrm{y}} \mathrm{O}\right|$, can be obtained as a function of the multipoles, that is, $\mathrm{U}=\mathrm{U}\left(\mathrm{b}_{3}, \mathrm{~b}_{5}, \ldots\right)$. In addition, it is realized that the structure of this function, $\mathrm{U}\left(\mathrm{b}_{3}, \mathrm{~b}_{5}, \ldots\right)$ depends on the shape of the uniform region, e.g. circle, ellipse, etc. For the case as shown in Fig.2, the field uniformity $U$ can be expressed approximately with $\mathrm{r}_{0}=20 \mathrm{~mm}$,

$$
\begin{gathered}
\mathrm{U}\left(\mathrm{b}_{3}, \mathrm{~b}_{5}, \mathrm{~b}_{7}, \ldots\right)=\operatorname{Max}\left(\left|\frac{\mathrm{B}_{\mathrm{y}}(\mathrm{r}, \theta)-\mathrm{B}_{\mathrm{y} 0}}{\mathrm{~B}_{\mathrm{y} 0}}\right|\right)= \\
\approx \operatorname{Max}\left(\left|\mathrm{b}_{3}+\mathrm{b}_{5}+\mathrm{b}_{7}\right|,\left|-\frac{\mathrm{b}_{3}}{3}+\frac{\mathrm{b}_{5}}{3}+\frac{\mathrm{b}_{7}}{2}\right|,\left|\mathrm{b}_{7}\right|\right)
\end{gathered}
$$

\subsection{Search of the Minimum Value of Field Uniformity from Multipoles}

For the BM1, the contour plot of the approximated field uniformity $\mathrm{U}=\mathrm{U}\left(\mathrm{b}_{3}, \mathrm{~b}_{5}, \ldots\right)$, as a function of the horizontal coordinates $\mathrm{x}_{1}$ and $\mathrm{x}_{2}$ of the upper main coil and lower main coil from the initial coil configuration, is shown in Fig.4. From this figure, the optimal value of $\left(\mathrm{x}_{1}, \mathrm{x}_{2}\right)$ is easily obtained.

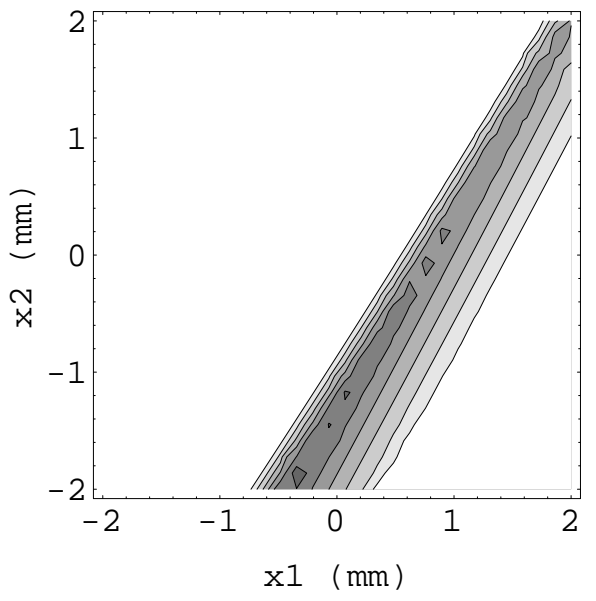

Fig. 4. Contour plot of field uniformity of $<0.2 \%$ of $\mid(\mathrm{By}-\mathrm{By} 0) / \mathrm{By} 0$. 


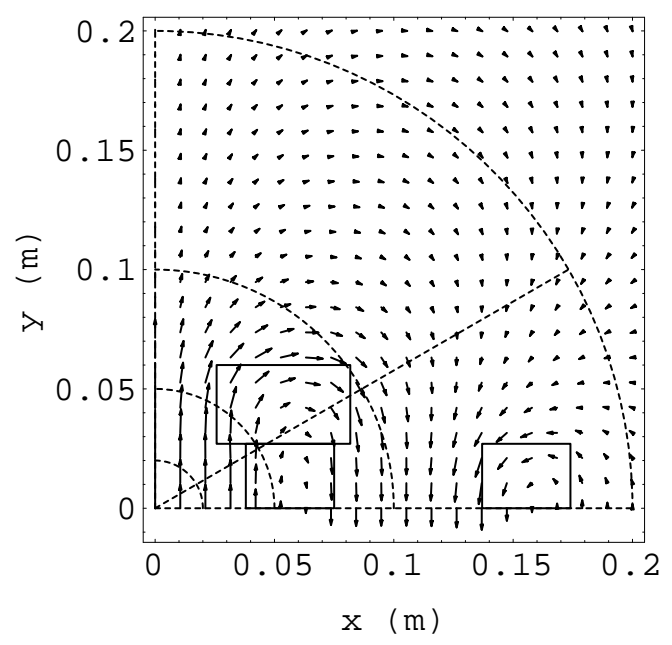

Fig. 5. Field distribution without the bias field and cross section of a active shield bending magnet.

\section{FIELD ANALYSIS}

In this field analysis, it is assumed that both main and shield coils are fabricated from the superconducting wire which permits the overall current density of $200 \mathrm{~A} \mathrm{~mm}^{-2}$. For the case without the vertical bias field of $-0.6 \mathrm{~T}$, the distribution of field vectors is shown in Fig.5, together with the cross sections of coils. The inversely vertical bias field - $\mathrm{B}_{\text {bias }}$ increases the total field between the main coils and the shield coils, and changes the location of the maximum field and the magnetic forces acting on each coil. The contour plot of $\left|\left(\mathrm{B}_{\mathrm{y}}-\mathrm{B}_{\mathrm{y} 0}\right) / \mathrm{B}_{\mathrm{y} 0}\right|$ is shown in Fig.6 The white region corresponds to the larger region of $\left|\left(\mathrm{B}_{\mathrm{y}}-\mathrm{B}_{\mathrm{y} 0}\right) / \mathrm{B}_{\mathrm{y} 0}\right|$, while the black region corresponds to the smaller region. The contour plot of $|\mathrm{B}|$ is also shown in Fig.7 The maximum field of coils is 5.5 T. Supporting structure for the magnetic forces should be optimized. The mechanical and cryogenic design are currently under study. Since the installation space for the bending magnet (BM1) is so limited, a compromise between the compactness for the whole structure and the easiness for the coil fabrication must be made.

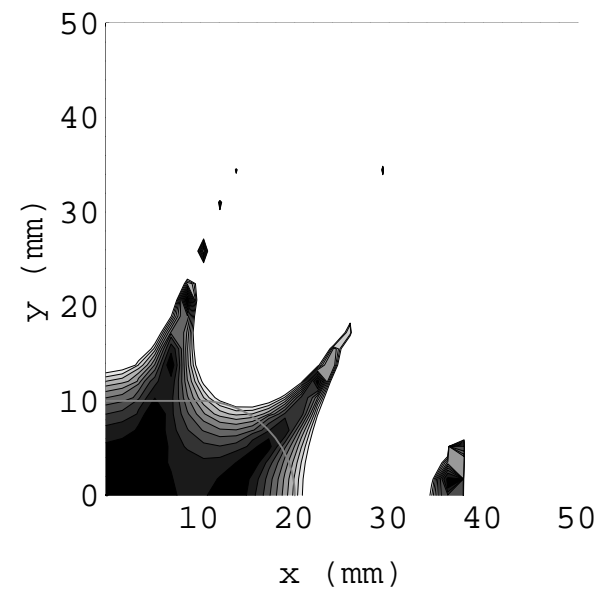

Fig. 6. Distribution of $|(\mathrm{By}-\mathrm{By} 0) / \mathrm{By} 0|$ of $<0.1 \%$.

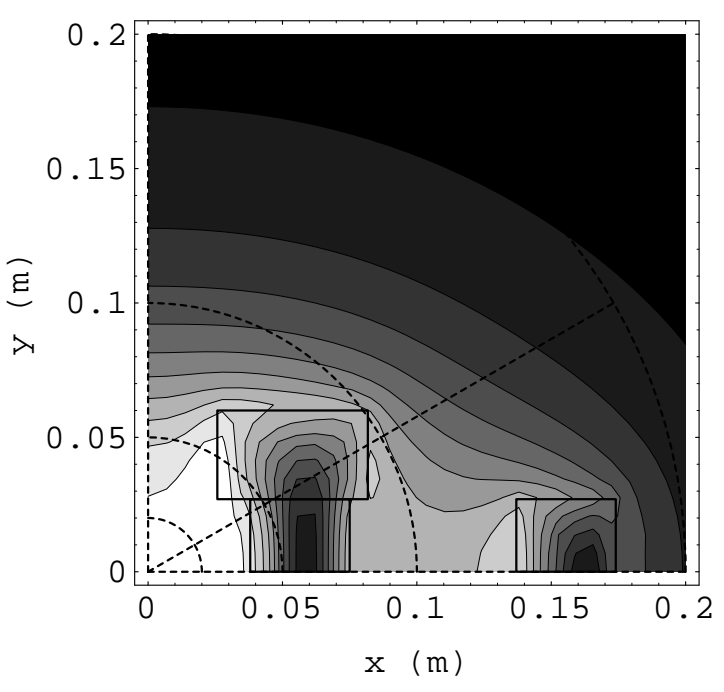

Fig. 7. Contour plot of $|\mathrm{B}|$ on the case without the bias field.

\section{CONCLUSION}

The relation between field uniformity and multipoles of dipoles was approximately obtained for the specific uniform region. It was recognized that this relation will be useful to optimize the cross-sectional shape of dipole coils such as the injection and extraction bending magnets of the SRC.

\section{REFERENCES}

[1] Y. Yano et al., "RIKEN RI-Beam Factory project", in this proceedings.

[2] T. Mitsumoto et al., "Orbit Analysis for the RIKEN Superconducting Ring Cyclotron", in this proceedings.

[3] H. Okuno et al., "Design Study of the Injection and Extraction Systems for the RIKEN Superconducting Ring Cyclotron", in this proceedings.

[4] S. Fujishima et al., "Numerical Analyses of the Injection and Extraction Trajectories for the RIKEN Superconducting Ring Cyclotron", in this proceedings.

[5] K. Halbach, "Fields and First Order Perturbation Effects in Two-dimensional Conductor Dominated Magnets", Nucl. Instr. and Meth. 78 (1970) pp.185198.

[6] H. Hirabayashi et al., "A Design Proposal for High Field Dipole Magnet", KEK 81-1 (1981).

[7] J. Rossbach and P. Schmüser, "Basic Course on Accelerator Optics", CAS, CERN94-01 pp.17-88 (1994).

[8] K. -H. Mess, P. Schmüser and S. Wolff, "Superconducting Accelerator Magnets", World Scientific, pp.45-63 (1996). 